\title{
Diversidades, resistências e justiça social
}

\section{Diversities, resistance and social justice}

\section{Diversidades, resistencias y justicia social}

\author{
Ana Lucia de Moura Pontes ${ }^{1, a}$ \\ Editora convidada \\ analupontes64@gmail.com | https://orcid.org/oooo-0001-9162-5345
}

\author{
Adriano De Lavor Moreira ${ }^{2, b}$ \\ Editor convidado \\ delavor@ensp.fiocruz.br | https://orcid.org/0000-0001-5653-1677
}
${ }^{1}$ Fundação Oswaldo Cruz, Escola Nacional de Saúde Pública Sérgio Arouca. Rio de Janeiro, RJ, Brasil.
${ }^{2}$ Fundação Oswaldo Cruz, Escola Nacional de Saúde Pública Sérgio Arouca, Revista Radis - Comunicação e Saúde. Rio de Janeiro, RJ, Brasil.

a Doutorado em Saúde Pública pela Fundação Oswaldo Cruz.
b Doutorado em Informação e Comunicação em Saúde pela Fundação Oswaldo Cruz.

Palavras-chave: Etnicidades; Diversidade; Desigualdade; Resistência; Comunicação; Saúde.

Keywords: Ethnicities; Diversity; Inequality; Resistance; Communication; Health.

Palabras clave: Etnicidades; Diversidad; Desigualdad; Resistencia; Comunicación; Salud.

A chamada pública para o dossiê temático Saúde, etnicidades e diversidade cultural: comunicação, territórios e resistências propôs construir um diálogo entre diversos campos de conhecimento acerca da determinação social da saúde dos diferentes grupos étnicos e analisar as relações existentes entre suas condições de saúde, suas possibilidades comunicativas e a efetivação de políticas públicas. O pressuposto dessa chamada foi destacar a luta histórica de diversos grupos por seus direitos territoriais e socioculturais e a construção de políticas públicas de saúde específicas no Brasil, no momento em que essas conquistas estão ameaçadas.

Os artigos que compõem esse dossiê expressam e dialogam com a mudança significativa no contexto sociopolítico do debate sobre justiça social e saúde. Se nas décadas de 1980 e 1990 justiça social era abordada numa perspectiva distributiva, que se revertia com reflexões acerca da distribuição de recursos e acesso a ações de saúde, no momento atual se agrega a necessidade de uma política de reconhecimento.

Fraser ${ }^{1}$ ressalta que, nos últimos anos, vivemos uma politização da cultura, que emergiu das lutas por identidade e diferença de vários grupos sociais, como mulheres, LGBTs (Lésbicas, Gays, Bissexuais, Travestis, Transsexuais e Transgêneros), negros e povos indígenas. Essas lutas geraram uma nova gramática e novas disputas nas reivindicações políticas, envolvendo questões de representação, identidade e diferença. Nesse âmbito, a autora sugere que as injustiças sociais podem se apresentar "na forma de subordinação de estatuto, assente nas hierarquias institucionalizadas de valor cultural"1, e que, portanto, os grupos sociais afetados exigem reconhecimento e transformação na ordem simbólica e na desconstrução dos valores subjacentes às diferenciações de estatuto. Fraser ${ }^{1}$ propõe agregar essas novas dimensões da justiça social à perspectiva 
de distribuição justa; afinal, a estrutura econômica mundial ainda gera pobreza, desigualdades sociais e de classe e, portanto, exige medidas distributivas. Assim, as políticas de saúde deveriam ser tensionadas tanto pelos aspectos distributivos quanto por aqueles de reconhecimento.

No debate das chamadas políticas de reconhecimento ou identitárias, nos interessa destacarmos as reflexões voltadas para a possibilidade de transformação do conjunto da sociedade na construção de relações mais democráticas entre os diferentes grupos étnicos e culturais, mas atentos às possíveis apropriações e ressignificações, por diferentes atores, que busquem neutralizar suas dimensões políticas².

Nesse sentido, nos interessa o debate intercultural que se coloca como um "ato político decisivo para o reconhecimento de sua especificidade cultural nativa e a visibilização da sua experiência histórica de adaptação/ resistência na ordem sociopolítica dominante".

Consideramos que a interculturalidade crítica pressupõe muito mais do que somente reconhecimento e valorização da diversidade étnico-cultural; ela envolve o questionamento das desigualdades e assimetrias construídas historicamente entre os diferentes grupos sociais (étnicos, de gênero, de raça, orientação sexual, entre outros). Portanto, envolve "assumir as diferenças como constitutivas da democracia e a construção de relações novas, verdadeiramente igualitárias entre os diferentes grupos socioculturais”3.

Essa perspectiva está próxima da adotada por Fraser ${ }^{1}$ quando, discordando das abordagens que somente reificam as identidades de grupo, sugere que a luta por reconhecimento está na instância de transformação do "estatuto individual dos seus membros como parceiros de pleno direito na interação social". E que, portanto, uma política de reconhecimento significa superar a subordinação desses grupos sociais com vistas à participação social como membro pleno da sociedade, buscando um "reconhecimento recíproco" $\mathrm{e}$ de "igualdade de estatuto". Para isso, Fraser considera que são necessárias duas condições: a primeira seria a "distribuição de recursos materiais que garanta a independência e 'voz' dos participantes"; "os padrões institucionalizados de valor cultural exprimam igual respeito por todos os participantes e garantam iguais oportunidades para alcançar consideração social"”.

A tarefa dos acadêmicos se direciona, então, para aprofundar e visibilizar o que Muniz Sodré aborda, na entrevista que concedeu à Reciis, ao revelar como as "relações das raízes" dos problemas e como o padrão de domínio étnico-ocidental do colonialismo branco o levam a concluir que "A forma da escravidão está incrustada na forma social brasileira"4. Nossa democracia se baseou em ideais que envolvem preferências de acordo com a cor de pele nas formas sociais, expressões do racismo, que outorgam ao negro ou indígena um lugar de cidadão de segunda classe. Sodré identifica o racismo como o "limite da aproximação da diferença" ${ }^{4}$, ampliando o debate sobre a suposta democracia racial e a cordialidade brasileira; ademais, destaca a importância de discutirmos o ódio como importante mecanismo de "exclusões da diferença"4.

Valorizamos enormemente a oportunidade de publicar a entrevista de Muniz Sodré, pois como um intelectual negro, aponta rupturas epistemológicas que emergem a partir de distintos lugares identificatórios étnicos. Assim como a nota de conjuntura de Luiz Henrique Eloy Amado, intelectual Terena, que destaca que a construção do Estado brasileiro se deu "a partir da perspectiva da desterritorialização, dominação e assimilação dos povos originários", levando ao extermínio de vários povos indígenas. Amado destaca o caráter autoritário do Estado brasileiro, que no seu processo colonial usou como estratégias as perspectivas de "integração" e de "branqueamento", visando ao apagamento das diversidades de pertencimentos étnicos existentes nesse território. No contexto atual, o Estado se torna o grande violador dos direitos humanos dos povos indígenas, levando ao retrocesso das demarcações de terras indígenas, ao aumento do desmatamento e das queimadas. São crescentes as denúncias de invasões de garimpeiros e madeireiros ilegais.

Mas cabe destacar que Amado retoma a "profunda capacidade de resistência qualificada" ${ }^{5}$ dos povos indígenas, que historicamente têm sido capazes de intensas mobilizações e articulações políticas, por intermédio de suas entidades representativas. Essa profunda capacidade de resistência política é um ensinamento dos povos indígenas para a sociedade nacional. 
Os artigos que compõem esse dossiê trazem contribuições importantes para esses debates, a partir de distintas perspectivas. Ressaltamos que questões de etnicidade, raça e gênero se transversalizaram nas análises, apontando contribuições dos estudos interseccionais para esse debate ${ }^{6}$.

Gessica de Castro Silva Viana e Fernanda Ariane Silva Carrera, no texto A (in)visibilidade da mulher negra youtuber, apontam que, apesar do avanço tecnológico que ampliou a participação das pessoas negras nas mídias sociais e ambientes online, ainda se reproduzem nesses espaços comunicacionais as desigualdades raciais e de gênero. Numa abordagem que busca destacar o empoderamento das mulheres negras e a importância da análise interseccional, analisam o alcance de canais de youtubers de mulheres negras e não negras. Destacam que o "espaço de debate não parece ser suficiente para fazer com que essas mulheres [negras] possuam alcance midiático eficiente", identificando que existem assimetrias na repercussão das produções realizadas por mulheres negras na plataforma YouTube. Entretanto, as autoras ressaltam que esses ambientes virtuais têm permitido às mulheres negras propagarem discursos anti-hegemônicos, antirracistas e antissexistas, e debaterem suas subjetividades e estética, numa perspectiva de empoderamento.

Outro estudo sobre produção midiática, que desvela os desafios no debate público sobre racismo, é o artigo de Ana Carolina Pontalti Monari e de Claudio Bertolli Filho, intitulado Entre o debate público e o silêncio: análise da cobertura jornalística online sobre a questão do suicídio de adolescentes e jovens negros no Brasil. A partir dos dados alarmantes divulgados na cartilha de Óbitos por suicídio entre adolescentes e jovens negros, de 2019, que apontou que a ocorrência de atentados contra a própria vida é $45 \%$ maior que entre brancos ${ }^{9}$, os autores analisam a cobertura dessa questão em três portais de notícias. Os resultados mostram o silêncio da mídia sobre o assunto e revelam um processo social de não-reconhecimento do racismo e das vozes das pessoas negras no debate público.

Também numa abordagem no campo da comunicação, o trabalho de Camila Escudero - A voz da mulher imigrante no debate público sobre o 'Projeto pró-cesárea no SUS' em São Paulo a partir da perspectiva da comunicação intercultural ${ }^{10}$ - apresenta o debate da construção do campo da interculturalidade e da comunicação intercultural como subsídio para a reflexão sobre o debate público a respeito do Projeto de Lei 435/2019, que determina que o parto cirúrgico (cesárea) deve ser uma opção da gestante. A autora relata, em seu artigo, casos de discriminação e maus-tratos de mulheres imigrantes na atenção pré-natal e no parto, ao mesmo tempo que registra atores e posicionamentos favoráveis e contrários à medida parlamentares, gestores, médicos especialistas, entidades profissionais, entre outros - evidenciando uma polifonia de vozes que pode emergir de uma questão complexa de saúde.

A partir de perspectivas etnográficas, apresentamos dois artigos sobre o contexto indígena no Chiapas, México. O artigo Lekil kuxlejal: Bem Viver na saúde autônoma do movimento zapatista, de Ana Paula Massadar Morel, aborda a concepção de saúde autônoma de comunidades zapatistas, na construção de um imaginário conceitual que possibilita a crítica ao capitalismo e ao colonialismo e a afirmação de outro mundo. A partir de conceitos em tzotzil, a autora desvela os sentidos que perpassam a concepção de lekil kuxlejal, ou de "Bem Viver”, e que são resgatados pelos mais velhos nas formações dos promotores de saúde.

Da mesma forma que $\mathrm{Amado}^{5}$ destacou com relação ao contexto brasileiro dos povos indígenas, os promotores de saúde zapatistas defendem que "não há saúde sem terra", pois, para eles, terra não é propriedade, "é mãe de todos". A terra significa a garantia de autonomia para esses povos. A autora aponta o caráter anticapitalista e descolonial do movimento zapatista, na sua resistência cotidiana aos avanços dos agrotóxicos e transgênicos no campo. Na saúde, destaca em particular a discriminação e os maustratos sofridos nos serviços de saúde, o que fortalece a retomada e valorização das práticas tradicionais, de parteras, hierberos e hueseros, num caráter autônomo e complementar à medicina ocidental.

$\mathrm{O}$ artigo de Morel nos faz retomar que, em contextos médicos plurais, como em territórios indígenas, há de se reconhecer e respeitar a negociação constante entre diferentes sistemas médicos e representações de saúde-doença. E, intermedicalidade se refere justamente ao âmbito da negociação e dos usos feitos 
pelos sujeitos no seu processo terapêutico dos diferentes elementos e práticas da medicina tradicional, biomedicina, autoatenção, entre outros ${ }^{12}$. Enfatizamos a atitude ativa dos povos indígenas ao se relacionarem com a sociedade nacional e com as distintas realidades sociomédicas ${ }^{13}$.

Abordando as práticas alimentares e relações de gênero, Renata Gabriela Cortez Gómez, no artigo Desigualdad en el acceso a alimentos de mujeres y niños zoques de México $^{14}$, procura trazer novas contribuições para a antropologia médica crítica, na análise dos problemas nutricionais em crianças indígenas, no município indígena de Ocotepec. Em um contexto onde cerca de $64 \%$ das crianças apresentam desnutrição crônica ou baixa estatura para a idade, a pesquisa aponta como as desigualdades de gênero e a economia de mercado afetam as práticas alimentares das famílias, particularmente, a amamentação e alimentação complementar nos primeiros anos de vida. O estudo demonstra como as relações complexas entre gênero, etnia e economia de mercado produzem desigualdades em saúde. Detalhando as interpretações e representações sociais envolvidas no processo de produção, distribuição, preparação e consumo de alimentos das crianças, a autora destaca a posição desigual das mulheres ocotepecanas e os impactos no estado nutricional dos seus filhos.

O conjunto de artigos deste dossiê temático demonstra a importância de estudos que abordem as complexas e diversas relações e interações de questões como etnicidades, diversidade cultural, gênero e racismo na determinação social e na produção de desigualdades em saúde. Destacamos as contribuições das áreas de comunicação e da informação em saúde que têm se aprofundado as perspectivas da população negra, mas apontamos os poucos estudos que visibilizam as vozes e o protagonismo indígena nessas áreas.

Para além de um olhar analítico sobre as práticas e os processos ambientados nos meios de comunicação tradicionais e o registro especulativo dos impactos do uso das novas tecnologias de informação e de comunicação, acreditamos que o debate deve fortalecer as discussões sobre as estruturas subjacentes que afetam a vida e determinação social da saúde dos diferentes grupos étnicos-culturais. É preciso também, além de identificar desigualdades e assimetrias entre grupos sociais - como alguns dos artigos aqui apresentados tão bem nos apresentam -, apontar caminhos e/ou estratégias que assegurem uma maior participação social desses grupos nas tomadas de decisão. Neste sentido, Sodré nos orienta que a comunicação é um novo modo de organização. "É um discurso de organização, reorganização do mundo e da consciência"4, aponta o teórico, assinalando a necessidade de reorganizar novas ferramentas de resistência. Luiz Henrique Eloy Amado nos indica os aprendizados possíveis a partir da "resistência qualificada" ${ }^{2}$ dos 519 anos de lutas dos povos indígenas brasileiros.

Em nosso entender, ampliar os espaços de registro e de escuta das demandas de grupos em situação de vulnerabilidade e/ou de invisibilidade é uma das ferramentas que possibilitam a 'contramovimentação'. É o compartilhamento de experiências, o contato entre corpos e discursos em seus territórios e a polifonia de vozes por eles produzida que revelam espaços e estratégias de resistência. A comunicação e a informação devem trabalhar no sentido de explorar ao máximo o potencial disruptivo desses encontros, de maneira a romper a fronteira que existe entre a simples existência e a ativa resistência.

As palavras 'resistência' e 'existência' têm sua origem ligada ao verbo latino 'sistere', cuja tradução para o português se aproxima de 'ficar firme, manter a posição'. Enquanto 'existir' deriva de 'exsistere' (sair de, elevar-se de; nascer, provir de, manifestar-se, mostrar-se), 'resistir' acrescenta 're' (para trás, contra). Refletindo sobre a origem e o uso destas palavras no cotidiano, podemos recorrer ao que afirma Santos ${ }^{15}$, quando chama atenção para a diferença entre o existente e o não existente, separados pelo pensamento abissal.

De um lado, aponta o teórico, está o sujeito "contemporâneo", integrado à sociedade metropolitana, com participação assegurada na tomada de decisões; de outro, o sujeito "atrasado", ainda sob a égide da sociedade colonial, que vive de acordo com os ditames da apropriação e da violência. O primeiro, existente; o segundo, inexistente. Entre os dois, uma linha abissal que decreta a validade de suas próprias condições de vida e de 
saúde. É na tensão desta linha de fronteira que se localiza o poder da "resistência". Tanto partindo de um lado, quanto de outro. Ambos estes sujeitos são resistentes; ambos por questão de sobrevivência.

O inexistente opera na resistência para se opor aos mecanismos que negam sua inclusão no mundo do conhecimento, do direito e doconhecimento, ou seja, no mundo da regulação e da emancipação. Resiste por reconhecimento. $\mathrm{O}$ existente resiste para defender sua condição privilegiada e não sucumbir ao outro lado da linha, para não se sujeitar aos ditames da apropriação e da violência.

Resistência é uma linha fluida de fronteira, de embate, permanente conflito e troca de conhecimentos. É neste ponto onde se situa a sua fragilidade e a sua fortaleza. Sugere-se reconhecer o potencial transformador que existe nesse local de resistência, que pode ser encarado como atitude, mas também como estratégia e local de enfrentamento de ideias ${ }^{15}$. Neste cenário, a comunicação é condição essencial para o tensionamento, a contramovimentação e a resistência que propõem Sodré e Amado neste dossiê.

Apesar do cenário político desfavorável no país, o potencial comunicativo resistente de índios, negros, mulheres, LGBTs e demais grupos invisibilizados aponta para a possibilidade de se identificar, enfrentar e superar desigualdades históricas e assimetrias que mantêm condições desfavoráveis de saúde. É neste sentido que o dossiê se coloca, como espaço de diálogo horizontal, de compartilhamento de adversidades e de conquistas. A comunicação e a informação são ferramentas de reorganização capazes de estabelecer um novo existir e um novo resistir: uma existência resistente; uma resistência que amplie a existência.

\section{Referências}

1. Fraser N. A justiça social na globalização: redistribuição, reconhecimento e participação. Rev Crítica Ciênc Soc. 2002;63:7-20.

2. Boccara G. La interculturalidad en Chile: entre culturalismo y despolitización. In: Langdon EJ, Cardoso MD, organizadoras. Saúde Indígena: políticas comparadas na América Latina. Florianópolis: Ed. da UFSC; 2015. p. 195-216.

3. Candau VMF. Educación intercultural crítica: construyendo caminos. In: Walsh C, organizadora. Pedagogías decoloniales:prácticas insurgents de resistir, (re)existir y (re)vivier. Tomo I. Abya Yala, 2013:145-61.

4. Sodre M. Do lugar de fala ao corpo como lugar de diálogo: raça e etnicidades numa perspectiva comunicacional. Rev Eletron Comunic Inf Inov Saude. 2019;13(4):877-86. doi: http://dx.doi. org/10.29397/reciis.v13i4.1944.

5. Amado LHE. Autoritarismo e resistência indígena no Brasil. Rev Eletron Comunic Inf Inov Saude. 2019;13(4):702-6. doi: http://dx.doi.org/10.29397/reciis.v13i4.1939.

6. Crenshaw K. Documento para o encontro de especialistas em aspectos da discriminação racial relativos ao gênero. Rev Estud Fem [Internet]. 2002 [citado em 2019 nov. 21];10(1):171-88. Disponível em http://www.scielo.br/scielo.php?script=sci arttext\&pid=S0104-026X2002000100011\&lng=pt\&nrm=iso. doi: http://dx.doi.org/10.1590/S0104-026X2002000100011.

7. Viana GCS, Carrera FAS. A (in)visibilidade da mulher negra youtuber. Rev Eletron Comunic Inf Inov Saude. 2019;13(4):707-24. doi: http://dx.doi.org/10.29397/reciis.v13i4.1884

8. Monari ACP, Bertolli Filho C. Entre o debate público e o silêncio: análise da cobertura jornalística online sobre a questão do suicídio de adolescentes e jovens negros no Brasil. Rev Eletron Comunic Inf Inov Saude. 2019;13(4):754-67. doi: http://dx.doi.org/10.29397/reciis.v13i4.1853.

9. Ministério da Saúde (BR). Óbitos por Suicídio entre Adolescentes e Jovens Negros 2012 a 2016 [Internet]. Brasília, DF; 2019 - [citado em 2019 nov 21]. Disponível em: http://bvsms.saude.gov.br/bvs/ publicacoes/obitos suicidio adolescentes negros 2012 2016.pdf.

10. Escudeiro C. A voz da mulher imigrante no debate público sobre o 'Projeto pró-cesárea no SUS' em São Paulo a partir da perspectiva da comunicação intercultural. Rev Eletron Comunic Inf Inov Saude. 2019;13(4):736-53. doi: http://dx.doi.org/10.29397/reciis.v13i4.1850.

11. Morel APM. Lekil kuxlejal: Bem Viver na saúde autônoma do movimento zapatista. Rev Eletron Comunic Inf Inov Saude. 2019;13(4):725-35. doi: http://dx.doi.org/10.29397/reciis.v13i4.1856. 
12. Langdon EJ. A construção sociocultural da doença e seu desafio para a prática médica. In: Baruzzi RG, Junqueira C, organizadores. Parque Indigena do Xingu: saúde, cultura e história. São Paulo: Terra Virgem/ Unifesp; 2005.

13. Gil LP. Políticas de saúde, pluralidade terapêutica e identidade na Amazônia. Saúde Soc. 2007;16(2):48-60.

14. Cortez Gomez RG. Desigualdad en el acceso a alimentos de mujeres y niños zoques de México. Rev Eletron Comunic Inf Inov Saude. 2019;13(4):768-83. doi: http://dx.doi.org/10.29397/reciis.v13i4.1893

15. Santos BS. Para além do pensamento abissal: das linhas globais a uma ecologia de saberes. Novos estud. - Cebrap. 2007;(79):71-94. doi: http://dx.doi.org/10.1590/S0101-33002007000300004. 